\title{
Application of Modified Bagasse as a Biosorbent for Reactive Dyes Removal from Industrial Wastewater
}

\author{
Abd El-Aziz A. Said ${ }^{1 *}$, Aref A. M. Aly ${ }^{1}$, Mohamed M. Abd El-Wahab ${ }^{1}$, Soliman A. Soliman ${ }^{1}$, \\ Aly A. Abd El-Hafez ${ }^{1}$, V. Helmey ${ }^{2}$, Mohamed N. Goda ${ }^{1}$ \\ ${ }^{1}$ Chemistry Department, Faculty of Science, Assiut University, Assiut, Egypt \\ ${ }^{2}$ Mechanical Engineering Department, Faculty of Engineering, Assiut University, Assiut, Egypt \\ Email: "aasaid55@yahoo.com
}

Received April 15, 2013; revised May 18, 2013; accepted June 25, 2013

Copyright (C) 2013 Abd El-Aziz A. Said et al. This is an open access article distributed under the Creative Commons Attribution License, which permits unrestricted use, distribution, and reproduction in any medium, provided the original work is properly cited.

\begin{abstract}
Propionic acid modified bagasse was used for the removal of reactive yellow 2 and reactive blue 4 . The effects of $\mathrm{pH}$, contact time, initial dye concentrations, adsorbent particle size and adsorbent dose on the adsorption of the two dyes were investigated. Additionally, the desorption process and intra-particle diffusion were studied. Acidic $\mathrm{pH}$ values were favorable for adsorption of both dyes. The equilibrium adsorption data were best fitted with the Freundlich isotherm for reactive yellow 2 and the Langmiur isotherm for reactive blue 4 . The values of their corresponding constants were determined. The kinetic for dye adsorption is well described by a pseudo-first order kinetic model for the reactive yellow 2 and by pseudo-second order for the reactive blue 4 . The investigation revealed that the hydroxyl groups of bagasse and the carboxylic group of propionic acid play a great role in the removal of both reactive dyes.
\end{abstract}

Keywords: Modified Bagasse; Reactive Yellow 2; Reactive Blue 4; Adsorption; Kinetics

\section{Introduction}

Dyes are widely used in many industries such as textile, plastic, paper, food and cosmetic for coloring their products. These dyes are water pollutants and cause environmental hazards. In addition, many dyes are difficult to be biodegradable and tend to persist in the environment creating serious water quality and public health problems. So, a conventional biological treatment process is not very effective in treating dyes wastewater. There are various methods for removing dyes including coagulation and flocculation [1], oxidation or ozonation [2] and membrane separation [3]. However, these processes are very expensive and cannot be effectively used to treat the wide range of dyes waste. Alternative methods include adsorption on natural biosorbents which are becoming now of high interest for removal of dyes from waste effluents. In this way several studies have used natural materials locally available, renewable and of low costs [4-6]. Among these sorbents are banana, bagasse, coir pith, palm-fruit bunch, apple-pomace, wheat straw, rice husk, pine sawdust, peanut hull, coffee husk, maize cob, orange peel, sugar cane dust and luffa fiber [7-9].

"Corresponding author.
Recently, sugarcane bagasse was used as potential lowcost adsorbent for removal of many dyes from wastewater [10-14].

Reactive dyes are generally used for colouring cotton and other cellulosic material, but are also applied to a small extent on wool and nylon. In the present study removal of reactive yellow 2 and reactive blue 4 from aqueous solutions using bagasse pre-treated with propionic acid was investigated. Several parameters have been studied such as $\mathrm{pH}$, contact time, biomass dosage, and particle size and desorption process. The equilibrium sorption capacity and the kinetic adsorption of both dyes on the modified bagasse were studied. The selection of bagasse for this study was based on low cost raw material and environmental impact.

\section{Materials and Methods}

Reactive yellow 2 and reactive blue 4 dyes were purchased from Sigma-Aldrish Chemical Co. The chemical structures of the two dyes are presented in Figure 1.

\subsection{Preparation of Adsorbent}

Sugar cane bagasse modified with propionic acid was previously described [13]. 


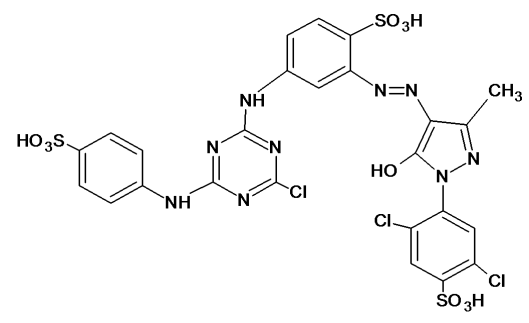

(a)

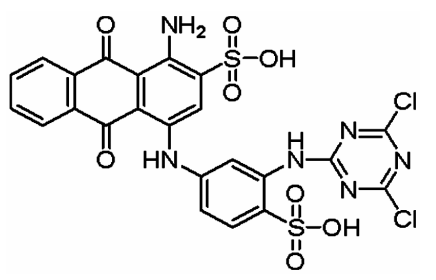

(b)

Figure 1. Chemical structures of reactive yellow 2(a) and reactive blue $4(\mathrm{~b})$.

\subsection{Preparation of Aqueous Dye Solution}

Stock solutions of the two dyes were prepared by dissolving accurately a weighed amount of each dye in distilled water $(1000 \mathrm{mg} / \mathrm{L})$ and diluting these solutions prior to performing the adsorption experiments.

\subsection{Adsorption Experiment}

In each adsorption experiment $50 \mathrm{~mL}$ of dye solution of known concentration and $\mathrm{pH}$ was added to known weight of adsorbent in $100 \mathrm{~mL}$ airtight volumetric flasks at room temperature $\left(27^{\circ} \mathrm{C} \pm 1^{\circ} \mathrm{C}\right)$ and the mixture was stirred on a rotary orbital Shaker at $150 \mathrm{rpm}$. The dye solution was filtered from bagasse and determined spectrophotometrically by recording the absorbance changes at maximum absorption (405 $\mathrm{nm}$ for reactive yellow 2 and $595 \mathrm{~nm}$ for reactive blue 4) using Thermofischer Scientific, aqua mate, Evolution 166 Uv-visible spectrophotometer. All $\mathrm{pH}$ measurements were carried out with a $\mathrm{pH}$-meter model number JENWAY 3450. The initial $\mathrm{pH}$ values were adjusted with $0.1 \mathrm{M} \mathrm{HCl}$ or $\mathrm{NaOH}$ to form series of pH's. Effect of adsorbent dosage was studied with different adsorbent doses and $50 \mathrm{ml}$ of the dye solution at equilibrium time. For the desorption studies the adsorbent used for the adsorption of the dye solution was thoroughly washed with distilled water to remove unadsorbed dye and desorption process was conducted at a range of $\mathrm{pH}$ values. The amount of dye adsorbed onto the bagasse, $q_{e}(\mathrm{mg} / \mathrm{g})$ was calculated as the following equation:

$$
q_{e}=\left(C_{i}-C_{e}\right) V / W
$$

where $C_{i}$ and $C_{e}$ are the initial and equilibrium time solution concentration of the dye $(\mathrm{mg} / \mathrm{L})$, respectively, $V$ the volume of the solution (L) and $W$ the dry weight of the sorbent $(g)$.

\subsection{Kinetic Studies}

To assess the applicability of the adsorption process it is necessary to determine the kinetic parameters, using the batch technique. A series of volumetric flasks containing $100 \mathrm{~mL}$ capacity, containing $50 \mathrm{~mL}$ dye solutions of known concentrations at the appropriate $\mathrm{pH}$ and were agitated by mechanical shaker at room temperature. After a definite time interval, the solutions were filtered and the filtrates thus obtained were then analyzed spectrophotometrically. All the experiments were duplicated and only the mean values are reported. The maximum deviation observed was less than $\pm 5 \%$.

\subsection{Thermal Studies}

Thermogravimetric analysis TGA and differential thermal analysis DTA techniques of original and treated with propionic acid $(5 \mathrm{wt} \%$ ) were carried out using a Shimadzu Thermal Analyzer model (TG $60 \mathrm{H})$. Curves of TGA and DTA were recorded upon heating up to $600^{\circ} \mathrm{C}$ at $10^{\circ} \mathrm{C} \cdot \mathrm{min}^{-1}$ and flow of air of $30 \mathrm{~mL} \cdot \mathrm{min}^{-1}$.

\section{Results and Discussion}

\subsection{Characteristics of Dyes}

Table 1 summarizes some important characteristics of reactive yellow 2 and reactive blue 4 dyes.

\subsection{Thermal Analysis}

Figure 2(a) shows that the decomposition of untreated bagasse proceeds in five stages. The first region of $\left(36^{\circ} \mathrm{C}\right.$ $124^{\circ} \mathrm{C}$ ) which accompanied with $5.3 \%$ weight loss with an endothermic peak minimized at $77^{\circ} \mathrm{C}$ is attributed to the physically adsorbed water. The second stage of $\left(125^{\circ} \mathrm{C}-\right.$ $208^{\circ} \mathrm{C}$ ) which accompanied with $8.1 \%$ weight loss is due to the dehydration water. The major weight loss $(53.2 \%)$ takes place within $\left(209^{\circ} \mathrm{C}-358^{\circ} \mathrm{C}\right)$ range which exhibit exothermic peak maximized at $316^{\circ} \mathrm{C}$. This peak is corresponded to the decomposition of cellulose and hemicelluloses in bagasse [14]. The fourth stage of $\left(359^{\circ} \mathrm{C}\right.$ $459^{\circ} \mathrm{C}$ ) and with exothermic peak maximized at $426^{\circ} \mathrm{C}$ and the fifth region of $\left(462^{\circ} \mathrm{C}-600^{\circ} \mathrm{C}\right)$ which accompanied with $4 \%$ weight loss with exothermic peak maximized at $480^{\circ} \mathrm{C}$ are attributed to the decomposition of lignin component of bagasse [14]. The TGA and DTA curves of treated bagasse with $5 \mathrm{wt} \%$ propionic acid was carried out and presented in Figure 2(b) and the data are cited in Table 2, it shows that the thermal decomposition of treated bagses proceeds in similar behaviour of untreated bagasse i.e., takes place in five stages. It is clear from the DTA curve and the data depicted in Table 2 that the addition of propionic acid retards the third decompo- 
Table 1. Characteristics of the used reactive dyes.

\begin{tabular}{ccccccccc}
\hline \multirow{2}{*}{ Dye } & $\lambda_{\max }(\mathrm{nm})$ & $\mathrm{C}(\mathrm{wt} \%)$ & \multirow{2}{*}{$\begin{array}{c}\text { No. of ionizable } \\
\text { groups }\end{array}$} & & \multicolumn{4}{c}{ No. of functional groups available for interaction } \\
\cline { 6 - 9 } & & 34.5 & 3 & $-\mathrm{SO}$ & $-\mathrm{C}=\mathrm{O}$ & $-\mathrm{NH}^{2}$ & $-\mathrm{Cl}$ & $-\mathrm{NH}_{2}$ \\
\hline Reactive yellow 2 & 404 & 35 & 2 & 6 & 1 & 2 & 3 & - \\
Reactive blue 4 & 595 & & 2 & 6 & 2 & 2 & 1 \\
\hline
\end{tabular}

Table 2. Data for thermal decomposition of untreated and treated bagasse.

\begin{tabular}{|c|c|c|c|c|c|c|}
\hline \multirow{2}{*}{ Adsorbent } & \multicolumn{5}{|c|}{ Temperature range $\left({ }^{\circ} \mathrm{C}\right)$ and weight loss $(\%)$} & \multirow{2}{*}{$\begin{array}{c}\text { Total weight loss } \\
(\%)\end{array}$} \\
\hline & $1^{\text {st }}$ stage & $2^{\text {nd }}$ stage & $3^{\text {rd }}$ stage & $4^{\text {th }}$ stage & $5^{\text {th }}$ stage & \\
\hline \multirow{2}{*}{ Original bagasse } & $36-124$ & $125-208$ & $209-358$ & $359-459$ & $462-600$ & \multirow{2}{*}{91.7} \\
\hline & 5.3 & 8.1 & 53.2 & 21.1 & 4.0 & \\
\hline \multirow{2}{*}{ Treated bagasse } & $36-123$ & $124-231$ & $232-357$ & $358-439$ & $440-600$ & \multirow[b]{2}{*}{96.6} \\
\hline & 3.7 & 11.5 & 54.7 & 24.1 & 2.6 & \\
\hline
\end{tabular}

sition step while enhances the fourth and fifth decomposition stages. This reflects that the presence of propionic acid strongly affected the structure of bagasse, i.e., a good interaction between bagasse and propionic acid. So, the results of thermal analysis indicated that propionic acid should affect the physico-chemical properties of bagasse.

\subsection{Effect of pH}

The $\mathrm{pH}$ of the dye solution has a great influence on the adsorption of the dye on the biosorbent presumably due to the effect on the surface properties of the adsorbent and ionization or dissociation of the dye molecules. Figure 3 represents the effect of $\mathrm{pH}$ on the removal of both dyes. The highest dye removal efficiency was observed at $\mathrm{pH}=1.9$ and $\mathrm{pH}=2.1$ for reactive yellow 2 and reactive blue 4 , respectively.

These acidic $\mathrm{pH}$ values might correspond to the rate of dissociation of the sulphonic acid groups located on the dyes. Furthermore, it is assumed that under acidic conditions the hydroxyl groups of bagasse and the carboxylic group of propionic acid are protonated i.e., $-\mathrm{OH}_{2}{ }^{+}$and $-\mathrm{COOH}_{2}{ }^{+}$. Thus a significant electrostatic interaction may occur between the positively charged sites of the adsorbent and the negatively charged part of the two reactive dyes (sulphonate groups) [15]. The lower adsorption of both dyes at alkaline $\mathrm{pH}$ values may be due to the presence of excess $\mathrm{OH}^{-}$ions competing with the dye anions for the adsorption sites.

\subsection{Effect of Agitation Time and Initial Dye Concentration}

The relation between removal of both dyes and the contact time was studied and the results are shown in Figure 4. It appears that removal of both dyes was rapid in the initial stages and then steadily increases with increasing time.

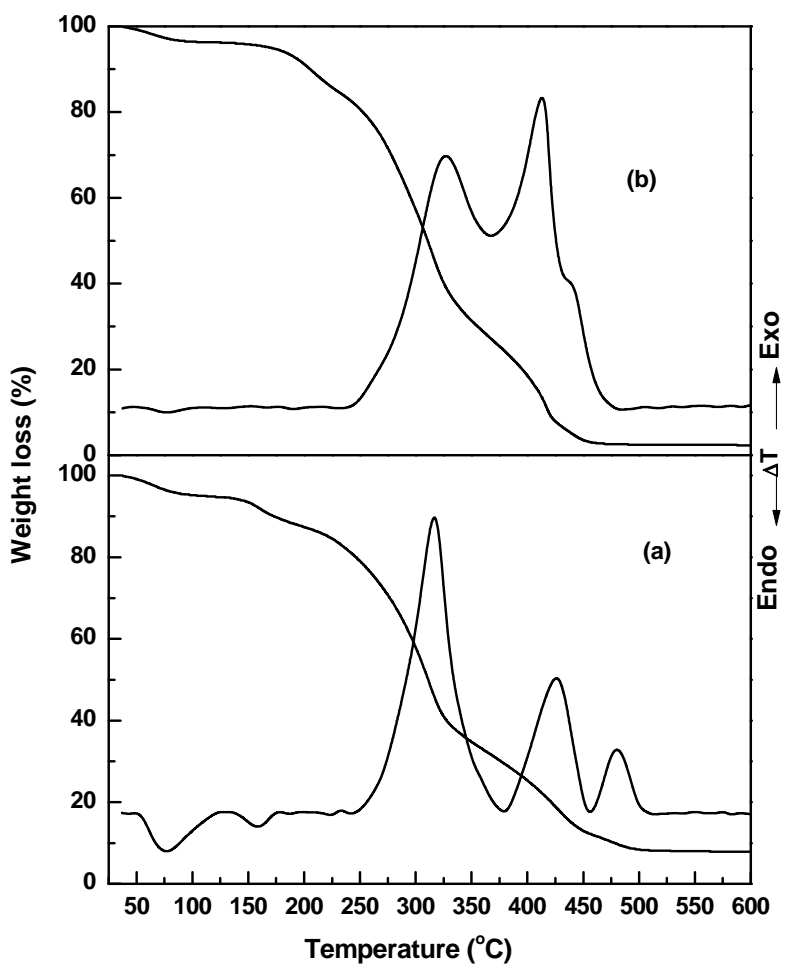

Figure 2. TGA and DTA curves of (a) untreated bagasse and (b) bagasse treated with $5 \mathrm{wt} \%$ propionic acid.

The rapid removal at the initial contact time may be ascribed to the availability of high positive charges on the bagasse surface for adsorption of the anionic reactive dyes. The subsequent slow adsorption of the two dyes is presumably correlated with the electrostatic repulsion between the adsorbed species onto the bagasse surface and the negative charge adsorbate species existing in the solution besides the slow pore diffusion of the dye into the bulk of the adsorbent [16]. Figure 5 shows the influence of the initial concentration of both dye solutions on the 


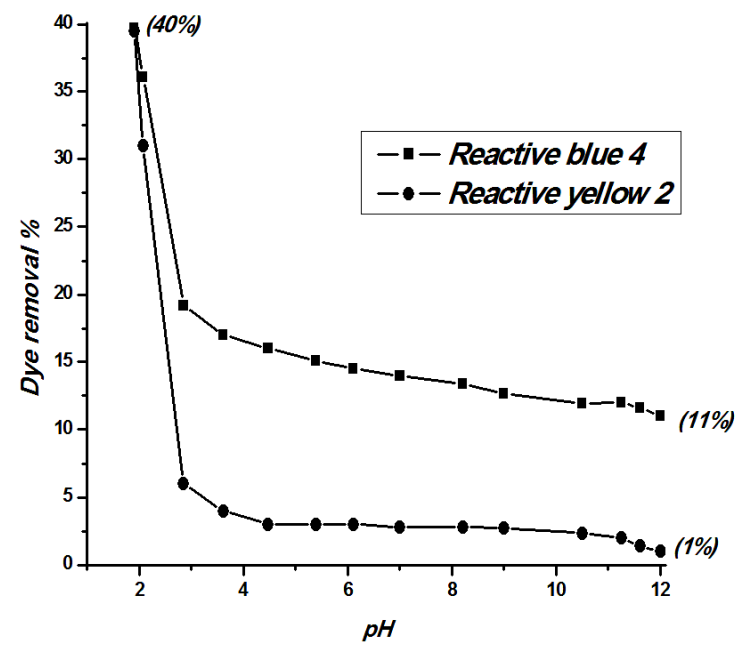

Figure 3. Effect of $\mathrm{pH}$ on dye removal, $(1 \mathrm{~g}$ of $1 \mathrm{~mm}$ particle size).

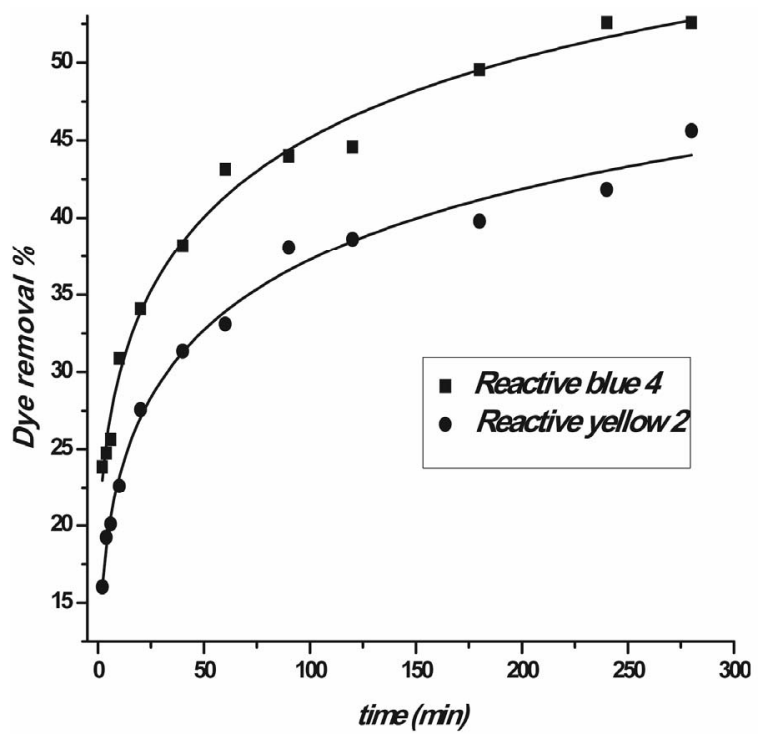

Figure 4. Effect of agitation time on dye removal.

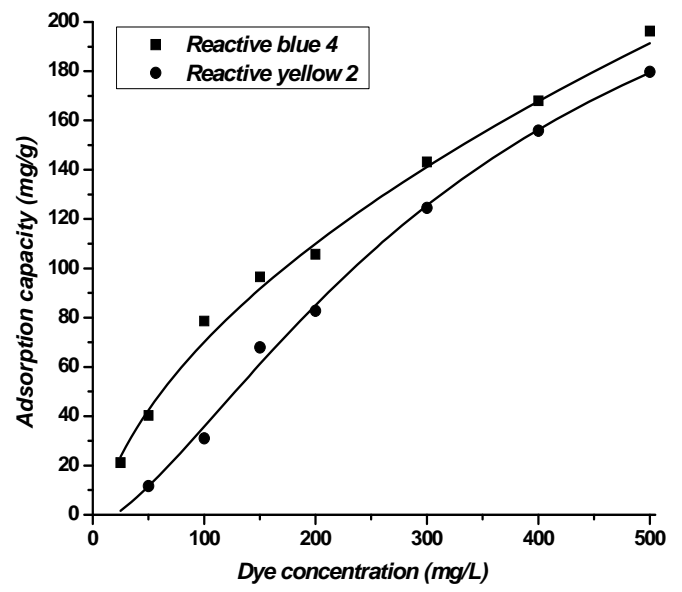

Figure 5. Effect of initial dye concentration on dye removal. adsorption dynamics by bagasse treated with propionic acid. Upon raising the initial dye concentration of the reactive yellow 2 from 50 to $500 \mathrm{mg} / \mathrm{L}$ the adsorbent capacity increased from 12.5 to $180 \mathrm{mg} / \mathrm{g}$ whereas for reactive blue 4 the capacity increases from 20 to 200 $\mathrm{mg} / \mathrm{g}$ when the initial dye concentration increased from 25 to $500 \mathrm{mg} / \mathrm{L}$.

\subsection{Effect of Sorbent Particle Size}

The effect of particle size on the adsorption of the two dyes onto the modified bagasse was studied (Figure 6), using a fixed sorbent dose $(25 \mathrm{mg} / 50 \mathrm{ml})$. Different particle sizes range i.e., $0.25,0.5,0.71$ and $1 \mathrm{~mm}$ were adopted. The results reveal that the percentage removal of the dyes increases with the decrease in bagasse particle size. Clearly a decrease in particle size would increase the surface area and consequently an increase in dye adsorption onto the bagasse surface occurs. Various factors are responsible for the low adsorption capacity of the dyes on the sorbent large particles. Among them are the diffusional path length or mass transfer resistance, contact time and blockage sections of the particles (not utilized for adsorption) [17].

\subsection{Effect of Sorbent Dosage}

The effect of adsorbent mass on the adsorption of the two dyes was investigated on treated bagasse of $1 \mathrm{~mm}$ particle size at initial dye concentration of $500 \mathrm{mg} / \mathrm{L}$. Figure 7 depicts the expected pattern for both dyes where the percent removal of each dye increases as the adsorbent dosage increases. This may be attributed to the increase in surface area of bagasse and availability of adsorption sites for the two reactive dyes. However, the adsorption density, the amount adsorbed by unit mass, decreases. This may be due to unsaturation of adsorption sites or

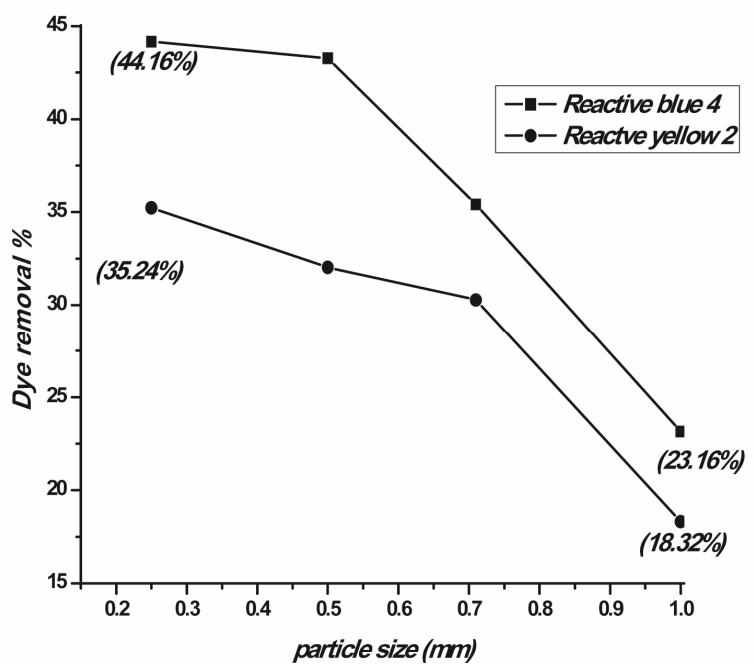

Figure 6. Effect of sorbent particle size on dye removal. 


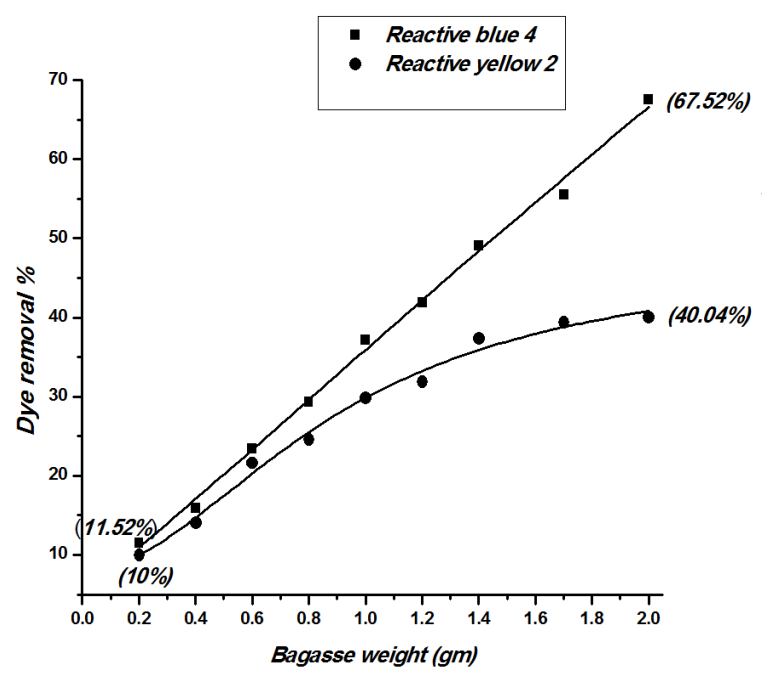

Figure 7. Effect of bagasse dosage on dye removal.

due to some sort of particle interaction such as aggregation which will decrease the total surface area of adsorbent and consequently an increase in the diffusion path length [18]. It is clear from the obtained results that the removal of reactive blue 4 is more pronounced relative to that of reactive yellow 2 upon increasing of the bagasse weight above $1 \mathrm{gm}$.

\subsection{Adsorption Isotherms}

The adsorption isotherms are important to optimize the design of an adsorption system to remove the dye. The parameters obtained from the different isotherms provide important information about the adsorption mechanisms and surface properties. The most widely accepted surface adsorption models are those of Freundlich and Langmuir.

\subsubsection{Freundlich Isotherm}

Freundlich isotherm is expressed as.

$$
q_{e}=K_{F} C_{e}^{1 / n}
$$

where $q_{e}(\mathrm{mg} / \mathrm{g})$ is the amount of dye adsorbed at equilibrium, $C_{e}(\mathrm{mg} / \mathrm{L})$ is the equilibrium liquid-phase concentration of the dye and $K_{F}$ is a constant related to the bonding energy and adsorption capacity. $1 / \mathrm{n}$ indicates the adsorption intensity of dye onto the adsorbent and the type of isotherm to be irreversible $(1 / \mathrm{n}=0)$, favorable $(0<1 / \mathrm{n}$ $<1)$ and unfavorable $(1 / \mathrm{n}<1)$.

Equation (2) can be arranged to a linear form:

$$
\log q_{e}=\log K_{F}+(1 / n) \log C_{e}
$$

To study the applicability of the Freundlich equation for dye absorption onto bagasse a linear plot of $\log \mathrm{q}_{\mathrm{e}}$ versus $\log C_{e}$ is plotted and presented in Figure 8 and the calculated parameters for Freundlich linear equation are shown in Table 3. The reactive yellow 2 adsorption by

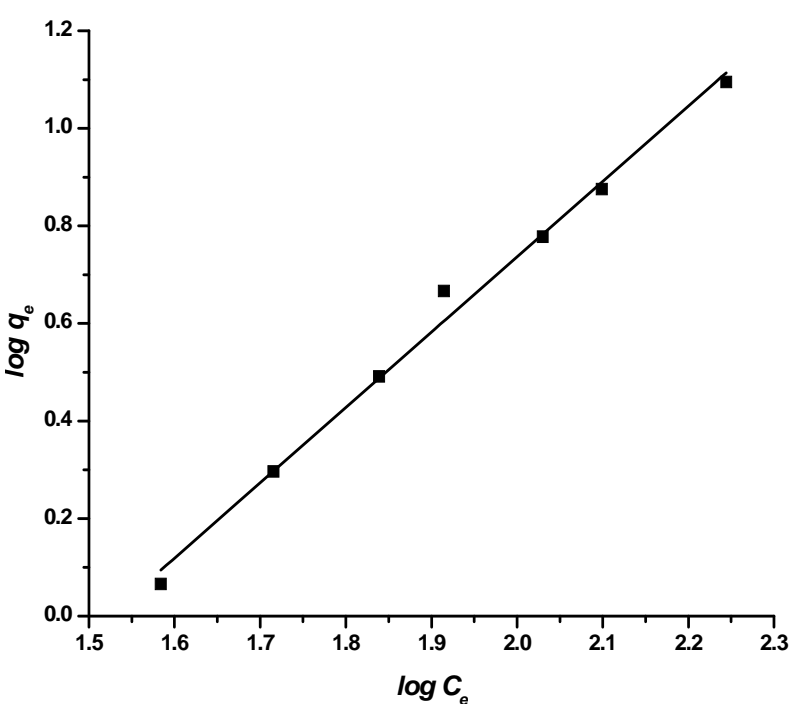

Figure 8. Freundlich isotherm for the sorption of reactive yellow 2 at $\mathrm{pH} 1.9$.

Table 3. Langmiur and Freundlich isotherm parameters for reactive yellow 2 and reactive blue 4 on modified bagasse.

\begin{tabular}{cccc}
\hline \multirow{2}{*}{ Dye } & \multicolumn{3}{c}{ Freundlich } \\
\cline { 2 - 4 } & $\mathrm{R}^{2}$ & $\mathrm{KF}$ & $1 / \mathrm{n}$ \\
\hline Reactive yellow 2 & 0.9916 & 0.0045 & 1.5439 \\
Reactive blue 4 & - & - & - \\
Dye & $\mathrm{R}^{2}$ & Qm(mg/g) & $\mathrm{a}(\mathrm{L} / \mathrm{mg})$ \\
Reactive yellow 2 & - & - & - \\
Reactive blue 4 & 0.9956 & 13.2 & 0.052 \\
\hline
\end{tabular}

modified bagasse fitted the Freundlich model well with $R^{2}$ $=0.9916$. The linear plot suggests the applicability of the Freundlich equation. The $1 / \mathrm{n}$ is lower than 1.0 , indicating that reactive yellow 2 is favorably adsorbed by the pretreated bagasse. On the other hand the linear plot of the Freundlich equation is not valid for reactive blue 4 .

\subsubsection{Langmiur Isotherm}

The Langmiur equation is expressed as follows:

$$
q_{e}=a Q_{m} C_{e} /\left(1+a C_{e}\right)
$$

where $q_{e}$ and $C_{e}$ are defined as in Freundlich equation, $Q_{m}$ is the maximum adsorption capacity and $\mathrm{a}$ is the Langmiur constant. Its linear form is expressed as:

$$
C_{e} / q_{e}=\left(1 / a Q_{m}\right)+\left(C_{e} / Q_{m}\right)
$$

The $Q_{m}$ and a values can be obtained from the slope $\left(1 / Q_{m}\right)$ and the intercept $\left(1 / \mathrm{a} Q_{m}\right)$ of the linear plot $C_{e} / q_{e}$ versus $C_{e}$. Figure 8 illustrates the linear form of Langmuir isotherm of the reactive blue 4 and the calculated pa- 
rameters are included in Table 3. It is clear from Figure 9 that the adsorption of the reactive blue 4 fits very well the Langmuir equation with $R^{2}=0.9956$ while the data do not fit with the Freundlich equation .

\subsection{Adsorption Kinetics}

In order to investigate the adsorption process of the reactive dyes by pretreated bagasse, pseudo-first order (Equation (6)) and pseudo-second order (Equation (7)) kinetic models were used.

$$
\log \left(q_{e}-q_{t}\right)=\log q_{e}-k_{1} t / 2.303
$$

And

$$
t / q_{t}=1 / h+t / q_{e}
$$

where $q_{e}$ is the amount of dye sorbed at equilibrium $(\mathrm{mg} /$ $\mathrm{g}), q_{t}$ is the amount of dye sorbed at time $\mathrm{t}(\mathrm{mg} / \mathrm{g}), k_{1}$ is the rate constant of the pseudo-first order sorption $\left(\mathrm{min}^{-1}\right), \mathrm{h}$ $\left(k_{2} q_{e}^{2}\right)$ is the initial adsorption rate $(\mathrm{mg} / \mathrm{g} \cdot \mathrm{min})$ and $k_{2}$ is the rate constant of pseudo-second order kinetics $(\mathrm{mg} / \mathrm{g}$ $\mathrm{min}$ ). Figure 10 shows that the pseudo first order equation fits well for the adsorption of reactive yellow 2 whereas the pseudo-second order equation is not valid. Moreover, the correlation coefficient $R^{2}$ and $K_{1}$ were calculated from the intercept and slope respectively and presented in Table 4 . The linear plot of $t / q_{t}$ versus $t$ for reactive blue 4 shows a good linear relationship, Figure 11. On the other hand the applicability of the pseudo-first order equation on the adsorption of reactive blue 4 was found not applicable. The correlation coefficient $R^{2}$ and $K_{2}$ were calculated from the intercept and the slope respectively and recorded in Table 4.

From Table 4, the correlation coefficients for the first and second order kinetic models are greater than 0.99 which led to believe that the first and second order equa-

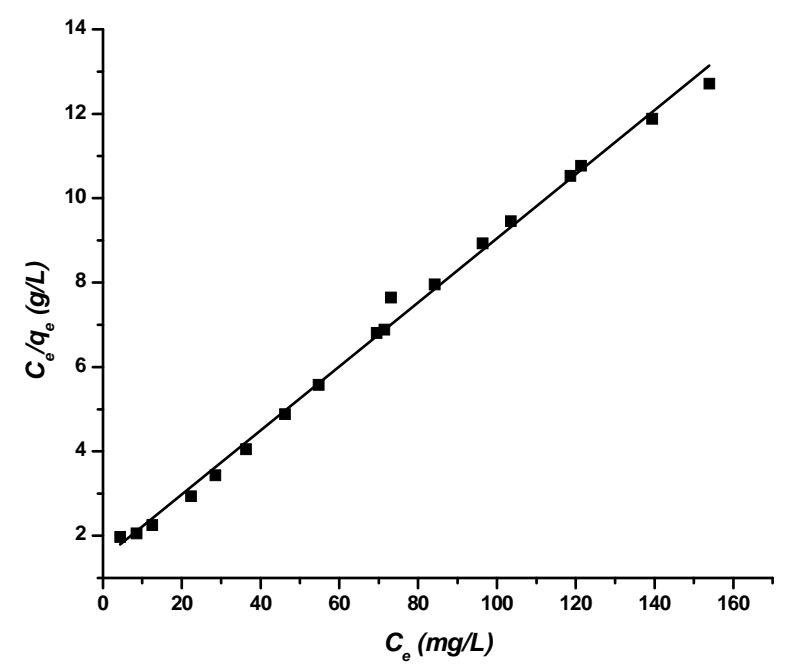

Figure 9. Linear form of the Langmuir isotherm for reactive blue 4 at pH 2.1.

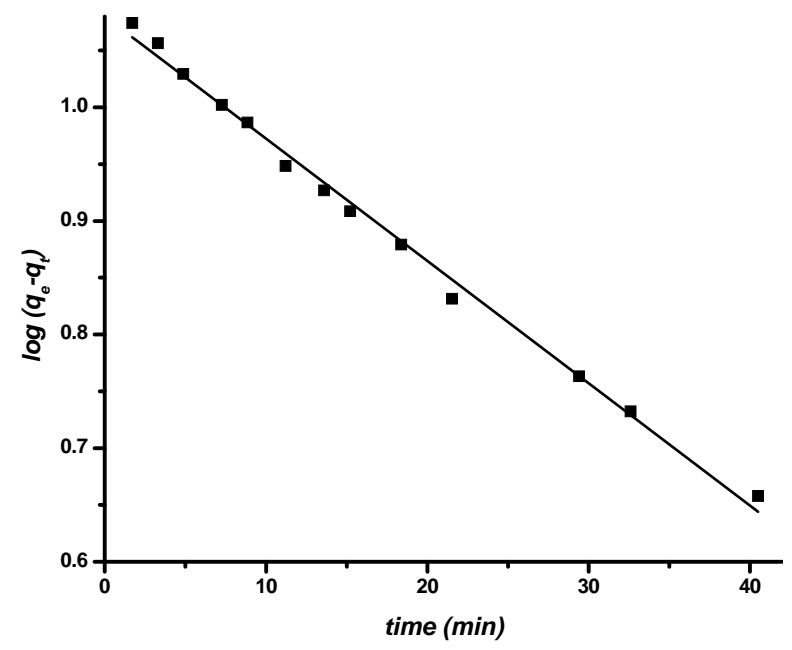

Figure 10. Pseudo-first order plot for the desorption of reactive yellow 2 at $\mathrm{pH}$ 1.9.

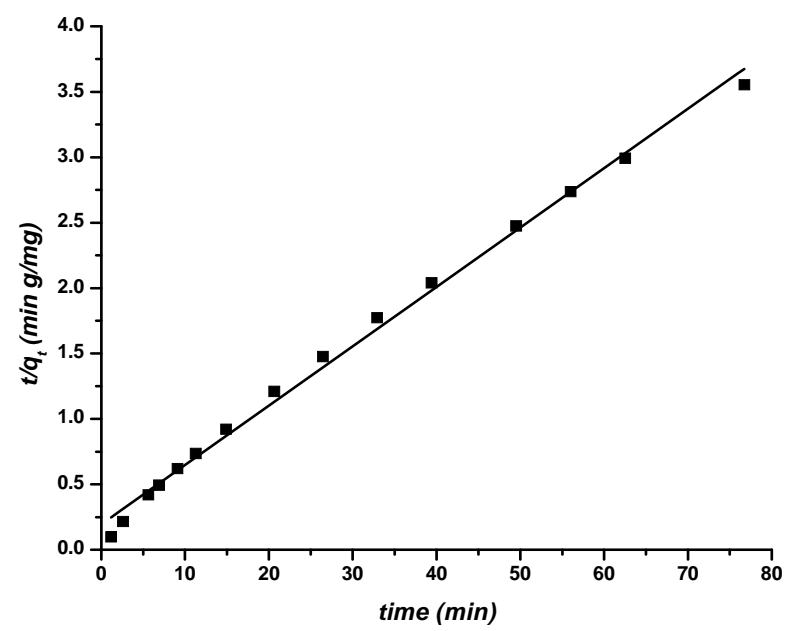

Figure 11. Pseudo-second order plot for adsorption of reactive blue 4 at pH 2.1.

Table 4. Comparison of the first and second order adsorption rate constants and the correlation coefficients.

\begin{tabular}{ccccc}
\hline \multirow{2}{*}{ Dye } & \multicolumn{2}{c}{ Pseudo-first order } & \multicolumn{2}{c}{$\begin{array}{c}\text { Pseudo-second } \\
\text { order }\end{array}$} \\
\cline { 2 - 5 } & $\mathrm{R}^{2}$ & $\mathrm{~K}_{1}\left(\mathrm{~min}^{-1}\right)$ & $\mathrm{R}^{2}$ & $\begin{array}{c}\mathrm{K}_{2} \\
\left(\mathrm{~g} \cdot \mathrm{mg}^{-1} \cdot \mathrm{min}^{-1}\right)\end{array}$ \\
\hline & & & & \\
$\begin{array}{c}\text { Reactive } \\
\text { yellow 2 }\end{array}$ & 0.9945 & 0.0248 & - & - \\
$\begin{array}{c}\text { Reactive blue } \\
4\end{array}$ & - & - & 0.9950 & 0.0106 \\
\hline
\end{tabular}

tions provided good correlations for the biosorption of reactive yellow 2 and reactive blue 4 respectively, on modified bagasse.

\subsection{Intra-Particle Diffusion}

The intra-particle diffusion model was applied to test the 
possibility of intra-particle diffusion of reactive yellow 2 and reactive blue 4 into pre-treated bagasse. The adsorption process involves a transport of solute from the aqueous phase to the surface of the solid particles with a subsequent diffusion of the dye molecules into the interior pores which is a slow process and is therefore, a rate determining step. The particle diffusion model is expressed by the following equation [19]:

$$
q_{t}=K_{d} t^{1 / 2}+C
$$

where $C(\mathrm{mg} / \mathrm{g})$ is the intercept and $K_{d}$ is the intra-particle diffusion rate constant $\left(\mathrm{mg} / \mathrm{g} \cdot \mathrm{min}^{-1 / 2}\right)$. Two intersecting linear plots are obtained for both dyes indicating diffusion of the dye molecules into macro- and micropores of bagasse. If the mechanism of adsorption follows on intra-particle diffusion process, the plot of $q_{t}$ versus $t^{1 / 2}$ should be straight line and pass through origin. Figure 12 shows that there are two separate regions that represent the steps involved during the process of adsorption. The initial straight line is due to the bulk diffusion while the second straight line corresponds to the intra-particle diffusion for both dyes. The plots were not best-fit straight lines passing through the origin. This phenomenon indicates that there is a boundary layer resistance. One of the possible reasons for the deviation of the straight line from the origin is that there is a difference in the rate of mass transfer in the initial and final stages of dye adsorption. The results of the experiment suggest that the intra-particle diffusion is not the only step controlling adsorption of the two dyes [20].

\subsection{Desorption and Reuse}

A further goal of any adsorbent used is reuse potential. So, before the investigation of reuse, the adsorption experiments were carried out to find the optimum $\mathrm{pH}$-desorption conditions. Figure $\mathbf{1 3}$ shows the effect of $\mathrm{pH}$ values on the desorption process of the two dyes. It shows that the two dyes are stable at lower $\mathrm{pHs}$ whereas increasing $\mathrm{pH}$ higher than 10 results in a rapid desorption of both dyes from bagasse surface. It is thus to be concluded that the two reactive dyes are stable in the $\mathrm{pH}$ range 3 - 10 for reactive yellow 2 and $6-10$ for reactive blue 4 while they may be completely recovered from the treated bagasse surface at $\mathrm{pH}=12$ and higher. It is of interest to mention here that these results are in agreement with the results presented in Figure 2 which show that the remarkable dye removal of both dyes on modified bagasse was at lower $\mathrm{pH}$ values.

\section{Conclusion}

Modified bagasse by propionic acid is an effective biosorbent for the removal of both reactive yellow 2 and reactive blue 4 dyes from wastewater. The maximum

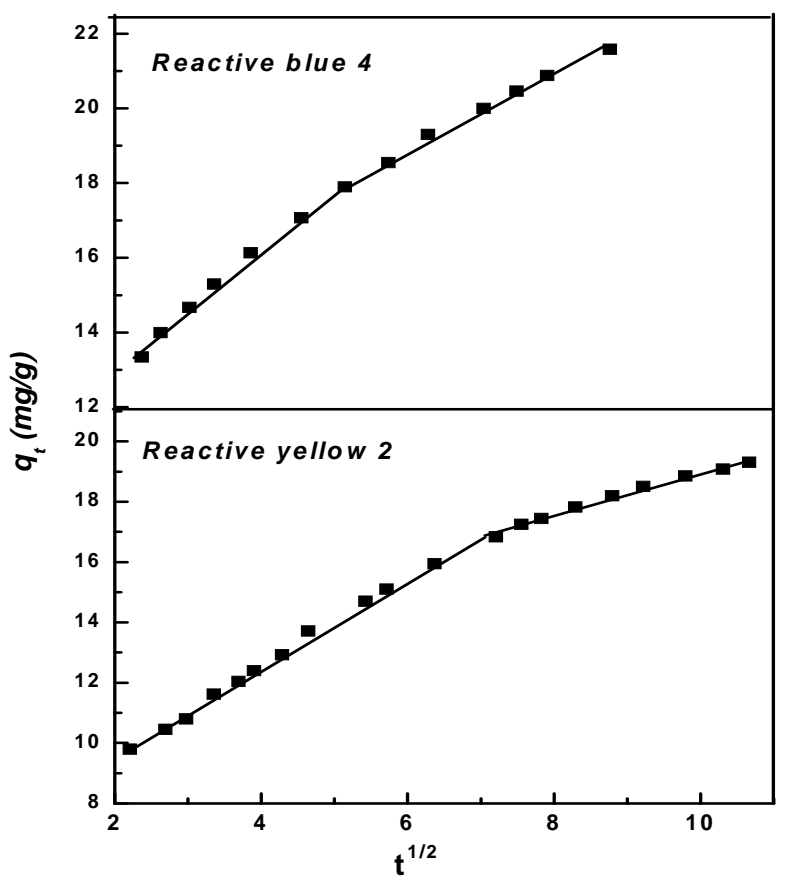

Figure 12. Intra-particle diffusion model for reactive yellow 2 at pH 1.9 and reactive blue 4 at pH 2.1.

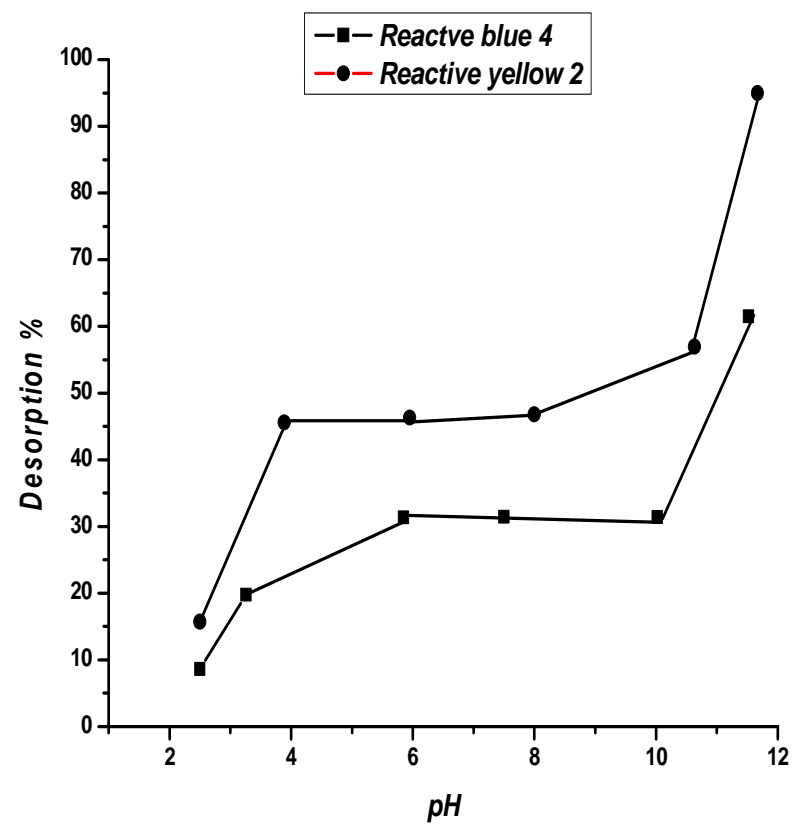

Figure 13. Effect of pH on the desorption process of the two dyes.

removal was observed at $\mathrm{pH}=1.9$ and $\mathrm{pH}=2.1$ for reactive yellow 2 and reactive blue 4, respectively. Moreover, the decrease of particle size of adsorbent was accompanied with a pronounced removal of both dyes. The equilibrium adsorption was best fitted with the Frundlich isotherm for reactive yellow 2 and with the Langmuir isotherm for reactive blue 4. Adsorption kinetics revealed 
that reactive yellow 2 is well described by a pseudo-first order whereas reactive blue 4 fits good for pseudo-second order. Modified bagasse can be reused by desorption of both dyes in the $\mathrm{pH}=12$ and higher. The hydroxyl and carboxylic groups from bagasse and propionic acid respectively enhance the removal of both reactive dyes.

\section{Acknowledgements}

The authors would like to thank the financial supports from the Science and Technology for Development Fund, STDF, Ministry of Higher Education, Egypt.

\section{REFERENCES}

[1] J. J. M. Orfao, A. I. M. Silva, J. C. V. Pereira, S. A. Barata, I. M. Fonseca, P. C. C. Faria and M. F. R. Pereira, "Adsorption of Reactive Dyes on Chemically Modified Activated Carbons-Influence of pH," Journal of Colloids and Interfaces Science, Vol. 296, 2006, pp. 480-489. doi:10.1016/j.jcis.2005.09.063

[2] P. K. Malik and S. K. Saha, "Oxidation of Direct Dyes with Hydrogen Peroxide Using Ferrous Ion as Catalyst," Separation and Purification Technology, Vol. 31, No. 3, pp. 241-250. doi:10.1016/S1383-5866(02)00200-9

[3] G. Ciadelli, L. Coris and M. Marcucci, "Membrane Separation for Wastewater Reuse in the Textile Industry," Resource Conservation and Recycling, Vol. 31, No. 2, 2000, pp. 189-197. doi:10.1016/S0921-3449(00)00079-3

[4] Z. Aksu and I. A. Isoglu, "Use of Agricultural Waste Sugar Beet Pulp for the Removal of Gemazol Turquoise Blue-G reactive Dye from Aqueous Solution," Journal of Hazardous Materials, Vol. 137, No. 1, 2006, pp. 418-430. doi:10.1016/j.jhazmat.2006.02.019

[5] T. Robinson, B. Chandran and P. Nigam, "Removal of Dyes from a Synthetic Textile Dye Effluent by Biosorption on Apple Pomace and Wheat Straw," Water Resources, Vol. 36, No. 11, 2002, pp. 2824-2830.

[6] Y-S. Ho, T-H. Chiang and Y-M. Hsueh, "Removal of Basic Dye from Aqueous Solution Using Tree Fern as a Biosorbent," Process Biochemistry, Vol. 40, No. 1, 2005, pp. 119-124. doi:10.1016/j.procbio.2003.11.035

[7] V. K. Gupta and Suhas, "Application of Low-Cost Adsorbents for Dye Removal-A Review," Journal of Environmental Management, Vol. 90, No. 8, 2009, pp. 2313-2342. doi:10.1016/j.jenvman.2008.11.017

[8] H. Demir, A. Top, D. Balkose and S. ülkü, "Dye Adsorption Behavior of Luffacylindrica Fibers," Journal of Hazardous Materials, Vol. 153, No. 1-2, 2008, pp. 389-394. doi:10.1016/j.jhazmat.2007.08.070

[9] N. M. Mahmoodi, M. Arami, H. Bahrami and S. Khorramfar, "Novel Biosorbent (Canola Hull): Surface Characterization and Dye Removal Ability at Different Cationic Dye Concentration," Desalination, Vol. 264, No. 1-2,
2010, pp. 134-142. doi:10.1016/j.desal.2010.07.017

[10] A. A. M. Aly, A. A. Said, A. A. Abd El-Hafez, M. N. Goda and V. Helmey, "Acid Pretreated Bagasse as a Suitable Biosorbent for Direct Red 81 Removal," Proceedings of 2010 International Conference on Environmental Engineering and Applications, 10-12 September 2010, Singapore, pp. 151-153.

[11] S. A. Saad, K. M. Isa and R. Bahari, "Chemically Modified Sugarcane Bagasse as a Potentially Low-Cost Biosorbent for Dye Removal," Desalination, Vol. 264, No. 1, 2010, pp. 123-128. doi:10.1016/j.desal.2010.07.015

[12] Z. Zhang, L. Moghaddam, I. M. O'Hara and O. S. W. Doherty, "Congo Red Adsorption by Ball-Milled Sugarcane Bagasse," Chemical Engineering Journal, Vol. 178, 2011, pp. 122-128. doi:10.1016/j.cej.2011.10.024

[13] A. A. Said, A. A. M. Aly, M. M. M. Abd El-Wahab, S. A. Soliman, A. A. Abd El-Hafez, V. Helmey and M. N. Goda, "Potential Application of Propionic Acid Modified Sugarcane Bagasse for Removal of Basic and Acid Dyes from Industrial Wastewater," Resources and Environment, Vol. 2, No. 3, 2012, pp. 93-99. doi:10.5923/j.re.20120203.03

[14] G.-B. Jiang, Z.-T.lin, X.-Y. Haung, Y.-Q. Zehang, C.-C. Ren, C.-K. Haung and Z.-Y. Haung, "Potential Biosorbent Based on Sugarcane Bagasse Modified with Tetraethylenepentamine for Removal of Eosin Y," International Journal Biological Macromolecules, Vol. 50, No. 3, 2012, pp. 707-712. doi:10.1016/j.ijbiomac.2011.12.030

[15] M. A. Kalaf, "Biosorption of Reactive Dye from Textile Wastewater by Non-Viable Biomass of Aspergillusniger and Spirogyra sp," Bioresource Technology, Vol. 99, No. 14, 2008, pp. 6631-6634. doi:10.1016/j.biortech.2007.12.010

[16] Y. S. Al-Degs, M. I. El-Barghouthi, A. H. El-Sheikh and G. M. Walker, "Effect of Solution pH, Ionic Strength, and Temperature on Adsorption Behaviour of Reactive Dyes on Activated Carbon," Dyes and Pigments, Vol. 77, No. 1, 2008, pp. 16-23. doi:10.1016/j.dyepig.2007.03.001

[17] M. Özacar and I. A. Sengil, "Adsorption of Metal Complex Dyes from Aqueous Solutions by Pine Sawdust," Bioresource Technology, Vol. 96, No. 7, 2005, pp. 791795. doi:10.1016/i.biortech.2004.07.011

[18] L. J. Yu, S. S. Shukla, K. L. Dorris, A. Shukla and J. L. Margrave, "Adsorption of Chromium from Aqueous Solutions by Maple Sawdust," Journal of Hazardous Materials, Vol. 100, No. 1-3, 2003, pp. 53-63. doi:10.1016/S0304-3894(03)00008-6

[19] W. J. Weber and J. C. Morris, "Kinetics of Adsorption on Carbon from Solution," Journal of the Sanitary Engineering Division, Vol. 89, No. 2, 1963, pp. 31-60.

[20] Y. Bulut, N. Gozubenli and H. Aydin, "Equilibrium and Kinetics Studies of Adsorption of Direct Blue 71 from Aqueous Solution by Wheat Shells," Journal of Hazardous Materials, Vol. 144, No. 1-2, 2007, pp. 300-306. doi:10.1016/j.jhazmat.2006.10.027 